\title{
Barriers and (im)mobility in Rio de Janeiro (accepted version)
}

Authors:

Benjamin Motte-Baumvol, Université de Bourgogne-Franche-Comté -THEMA(UMR6049), France

Olivier Bonin, UPE-IFSTTAR - LVMT, France

Carlos David Nassi, Federal University of Rio de Janeiro, Brazil

Leslie Belton-Chevallier, UPE-IFSTTAR - DEST, France

Citation:

Motte-Baumvol, B., Bonin, O., David Nassi, C., Belton-Chevallier, L., 2016. Barriers and (im)mobility in Rio de Janeiro. Urban Studies 53, 2956-2972. https://doi.org/10.1177/0042098015603290

\section{INTRODUCTION}

Within the Municipality of Rio de Janeiro (MRJ), immobility or the share of people with no journeys on any given day is very high (46\%) (Motte-Baumvol and Nassi 2012). It is also very unevenly distributed. It can as much as double depending on the city district and is supposedly related to the uneven income distribution among individuals that is central to differences in mobility among Brazilians, more generally. In large Brazilian cities, the poorest populations make almost half the average number of journeys as the richest (CENTRAL 2005; Vasconcellos 2005). The proportion of immobile individuals reaches 54.3\% among the poor as compared to $32.9 \%$ among rich households, which earn more than 20 times the minimum wage (CENTRAL 2005). But these marked differences cannot be explained by the massive income differences between rich and poor in Brazil alone. For Vasconcellos (2005), the reason is probably to be found as well in unemployment and underemployment. The high levels of unemployment, inactivity and casual work among the poor mean fewer work-related journeys and define the main categories of population concerned by immobility. Thus the low rate of activity of the Brazilian population, especially women, is thought to be related to the lower level of mobility and the high immobility reported for Rio de Janeiro. Motte-Baumvol and 
Nassi (2012) went further in analysing the specific features of MRJ by showing that the differences in mobility and immobility between the different districts were primarily due to population structure effects, with the proportion of working age population and working age population in employment being far lower in the northern districts of MRJ. Yet, although population structure effects prevail, spatial factors such as the severance effect (Appleyard and Lintell 1972, Appleyard et al. 1981) may also account for differences between districts.

Indeed, Rio de Janeiro features many different types of barriers that may affect immobility in several districts and for several population groups. These barriers may be physical or symbolic and perceptive. Physical barriers (Noonan 2005) relate especially to the physical characteristics of the site of the city with its winding coastline, bay, islands and its many steep hills. Physical barriers are also formed by major single-purpose zones and major transport infrastructures that can only be crossed at the cost of substantial effort and diversions and tend to reduce the mobility of populations living nearby (Héran 2011, 2009). Symbolic and perceptive barriers (Capron 2002) correspond to the social fragmentation of space, notably due to the very marked spatial segregations in Rio de Janeiro. Santos (1990) emphasises the isolation created by fragmentation especially for certain poor districts wedged between rich districts, infrastructures and the physical environment. In such districts, the relative immobility of much of the population is the outcome, for that commentator, of poverty, low wages and geographical conditions.

This study proposes therefore to identify the scope of two types of barriers that we shall call physical barriers and social fragmentation as they affect immobility. Immobility is understood here as the absence of travel, as the fact that people didn't make any journey during the day of the survey. The challenges relating to immobility and spatial effects are important, since for Lévy (2000), individually, people who are immobile are in a situation of confinement or even imprisonment. Collectively, immobility or 'home-territory arrest' of a large number of people 
would lead the city to become a set of ghettos and would transform fragmentation into disintegration (Santos, 1990).

Our findings from the latest Household Travel Survey (HTS) (CENTRAL 2005) available for the metropolitan area of Rio de Janeiro (2003) illustrate the effects of the two types of barrier on immobility that more specifically mark out certain categories of individuals such as housewives, the elderly, the unemployed or poor workers. Conversely, the wealthier active population seems to be little affected by the two types of barriers under study. Lastly, our results show that social fragmentation does not necessarily lead to greater immobility of favela populations. On the contrary, for the favelas in heart of rich districts, it tends to increased mobility, especially for population in employment or looking for employment.

\section{LITERATURE REVIEW}

The social dimension of immobility: from relational isolation and exclusion to inequalities

Contemporary ideas about mobility (Barrère and Martuccelli 2005) value mobility to the detriment of immobility. Supposedly everything is mobility and any feeling of immobility ought to be countered. In a social context in which mobility is the distinctive and differentiating factor (Boltanski and Chiapello 1999; Rémy 1996), being immobile is synonymous with exclusion and relational isolation because immobility corresponds antagonistically to an absence of mobility, regardless of the reference space or form of mobility (Montulet 2005). For authors who defend a new paradigm of mobility or mobility turn (Adey 2006; Cresswell 2010; Hannam, Sheller and Urry 2006; Urry 2007), mobility and immobility are, however, 'neither a dualism nor an opposition rather a relational continuum’ (Pellegrino 2011). For Creswell (2010), mobility may be compared with breathing punctuated by phases of relative immobility even when the individual remains active. For Urry (2007), mobility requires these 'mooring' 
phases in order to maintain fluidity in time and space. Lastly, the immobility of infrastructures is also the inescapable support of mobility (Hannam et al. 2006).

In its everyday meaning, that is, as an individual absence of day-to-day physical movement, immobility reveals inequalities among several categories of population: the elderly versus younger people (Pochet 2003), women versus men (Uteng and Cresswell 2008), poor households versus well-to-do households (Orfeuil 2004), and so on. The absence of movement and the high proportion of immobile persons within a population may often be interpreted as the sign of a poorly operating society, in which individuals have little interconnection and communicate little (Park 1926). From this standpoint, the level of immobility observed in Rio de Janeiro might seem somewhat worrying. Several factors tend to nuance this conclusion. Apart from methodological consideration on how to measure inequalities in travel surveys in general and for Rio de Janeiro in particular (cf. below), several studies have looked into mobility and therefore the immobility of poor households. Their travel strategies tend to combine mobility and locality in a particular way, so they can take advantage of the resources they have close to home (Bacqué and Fol 2007; Fol 2009) and their local implantation (Coutard et al. 2004). While the immobility of poor households is never total, their movements are characterised by their lower use of individual motor transport and their shorter range (Orfeuil 2004). In this way, depending on the scale of analysis, immobility may be mistaken for localism or proximity. Thus, poor households prefer to decline job offers that are too remote so as to avoid harassing and expensive journeys. This option may prove positive in the longer term for the living conditions of individuals and their families (Jouffe and Lazo Corvalán 2010).

While the poorest households are never totally immobile, the phenomenon does reveal social differences and a relative spatial enclosure, on the scale of the home and its immediate vicinity, the district, and therefore ultimately gives leverage to segregation or develops it among social classes. In this, immobility has both a social and a geographical dimension. Without totally 
excluding the first dimension, the objective of this article is to grasp more finely the geographical scope and mainsprings of immobility.

\section{Another dimension of immobility: the geographical component}

While the social dimension of immobility is often analysed and investigated, its geographical dimensions remain underexplored. However, several effects arise more directly from considerations that are as much, if not more geographical or spatial than sociological or social.

\section{Population structure effect}

Immobility is unequally distributed among individuals mainly depending on their activity status. In Rio de Janeiro (Motte-Baumvol and Nassi 2012), retired people and housewives are the main immobile categories. The unemployed are the third largest category. Conversely, workers and students are the categories with the lowest proportions of immobile people. The predominant link between immobility and work is also observed in France on the basis of the national HTS (Madre et al. 2007).

In highly segregated cities like Rio de Janeiro, poverty and unemployment are concentrated, in this instance in the north of the city. This is reflected by much larger numbers of unemployed and housewives in the north. This population structure effect explains the greater immobility observed in the poorer northern districts compared with the wealthier southern ones (MotteBaumvol and Nassi 2012).

\section{Severance effect}

Apart from population structure effects, other factors may lend a geographical dimension to immobility. This is particularly the case of major transport infrastructures that may locally form traffic barriers. Thus the inhabitants of a street with high volumes of traffic are separated from one another by the infrastructure and have fewer neighbourhood relations, they frequent the 
public space around their homes less often and live more confined in their homes (Appleyard and Lintell 1972; Appleyard et al. 1981). This is the severance effect. Traffic barriers include motorways, railway but also very busy main roads and streets (Hine and Russell 1993). James et al. (2005) highlight that traffic barriers also have a psychological dimension because they produce an atmosphere (unpleasant, insecure, etc.) and nuisances (noise, odours, transit, etc.) that curbs journeys within the neighbourhood.

While many British and American authors have concentrated on traffic barriers, some of their observations and analyses apply to all types of barriers that can be found in urban space. The severance effect is not specific to transport infrastructures alone but can be bound with all large single-purpose elements (Jacobs 1961), such as industrial zones, airports, sports stadiums or docks. The physical environment may also form barriers. In Rio de Janeiro, the natural site of the city has many barriers such as the steep relief, the coastline, the island, as well as the bay and the protected forest that are both in the heart of the metropolitan space.

The existence of barriers is not necessarily harmful for travel beyond the immediate vicinity if each of the zones separated from others by the boundary is large enough to be multifunctional (Jacobs 1961; Héran 2009). But when the districts are too small or broken up and/or the barrier is very difficult to cross, the whole zone is then marked by the severance effect and the mobility number of journeys of residents declines in intensity. For Héran (2011), the indirect effects of barriers are disaffection for active modes, reduction in neighbourhood relations, and damage to health and living conditions. For this author, the populations most vulnerable to barrier are children, people whose mobility is reduced, pedestrians and cyclists. The barriers require them, among other things, to make detours and go up and down hills, expend additional energy expenditure and/or take dangerous crossings with which these populations have more difficulty.

Social fragmentation 
Beyond physical barriers, symbolic and perceptive barriers (Capron 2002) may form impediments to mobility. They arise in particular from the very marked sociospatial segregation of South American and Brazilian metropolises (Rodríguez and Arriagada 2004; Sabatini 2006). In Brazil, the term fragmentation is used to describe this situation (Santos 1990). Fragmentation goes beyond the separation of social groups in space because it expresses a more rigid separation, gaps that are impossible to close (Chétry 2013). Fragmentation is represented through the spatial and social morphology of the city (Guerrien 2004). It is defined as the juxtaposition of blocks separated by various forms of barriers that may be built (walls, transport infrastructures, large footprints), physical (reliefs, island status), social (inequalities, security) or functional. Santos (1990) highlights the isolation created by fragmentation, in particular, for certain poor districts trapped between rich districts, infrastructures and the physical surroundings. In such districts, the author claims that the relative immobility of a large proportion of the population arises from poverty and low wages but also from their living conditions. He concludes that the immobility of so many people is leading the city to become an array of ghettos and is changing its fragmentation into disintegration.

\section{STUDYING IMMOBILITY ON THE BASIS OF THE HTS}

Of the 99,300 individuals surveyed in the Rio de Janeiro Metropolitan Area (RJMA) HTS, 57,419 lived in the MRJ and were selected for use in this research. The HTS reveals a low level of mobility among RJMA inhabitants (1.8 journeys per inhabitant per day), compared to European or North American cities, but similar to other Brazilian cities (Vasconcellos 2005). For workers, the number of journeys was just 2.4 per day. Another prominent characteristic of 
movements in Brazilian cities and of Cariocas ${ }^{1}$ is mode sharing. Only $15 \%$ of journeys were made by car, which boosts the figure for public transport to $46.4 \%$ of journeys. Lastly, $34 \%$ of journeys were made on foot.

The low number of journeys by Cariocas can be explained by the high proportion of individuals making no journeys and which brings the average down. Some $46 \%$ of individuals made no journey on the day selected for the survey. This percentage of immobile inhabitants is far higher than in European countries, where it ranges from 10 to 26\% depending on the country, source and type of population under study (Hubert et al. 2008). However, it is similar to that measured for Sao Paulo, another major Brazilian city. Vasconcellos (2005) reports that the level of immobility there varies from 24 to 55\% depending on the individual's income level.

Immobility measured by the HTS usually corresponds to an isolated episode. HTSs provide no more than a snapshot of one day of mobility and ignore life patterns and organisation over several days that may characterise individuals' mobility (Axhausen et al., 2007; Axhausen et al., 2002). An individual who is immobile one day is often mobile the other days, as revealed by surveys made over several days or weeks. Those surveys show that recurrent immobility concerns just 5\% and 8\% of the population (Axhausen et al. 2007, 2002; Chlond et al. 1999) for all of the areas studied (Madre et al. 2007).

Immobility is probably overestimated in the Rio de Janeiro HTS and in HTSs generally. First, very short duration or very short distance journeys are ignored (Madre et al., 2007; MotteBaumvol and Nassi, 2012). Thus, in the Rio de Janeiro HTS, unlike European or North American HTSs, journeys of less than 300 m made on foot are not counted. While it is difficult to quantify the number of individuals involved, Motte-Baumvol and Nassi (2012) report that it

\footnotetext{
${ }^{1}$ The inhabitants of the municipality of Rio de Janeiro are called Cariocas.
} 
corresponds to $5 \%$ of respondents in the Paris Region HTS which takes account of such journeys. Another factor of overestimation of immobility in HTSs stems from soft refusal, which is when the respondent fails to declare a journey or activity so as to end the interview more quickly. This non-declaration bias is particularly important in telephone surveys (Armoogum et al. 2005) but much more limited in face-to-face interviews as in the Rio de Janeiro HTS. Even so, Madre et al. (2007) think there is 3\% of soft refusal among individuals surveyed face-to-face. Considering these two limits, Madre et al. (2007) consider that based on the 1993-94 HTS in France, the immobility values might be between 8 and 12\% rather than the $18 \%$ measured.

The question of the reasons for the absence of journeys does not feature in most HTSs. So the factors of immobility can only be addressed from the sociodemographic variables of individuals and their households. Based on these variables, in France, Madre et al. (2007) report three main determinants of immobility: old age, occupational status and in particular non-activity, and lastly place of residence. Living in a sparsely-populated zone, a small city or the outskirts of an agglomeration increases the chances of being immobile. The same authors report two subsidiary factors: owning a vehicle or holding a driving licence, and low income. They also observe that some factors have no influence on the level of immobility: educational level, working hours or the household's audio-visual equipment.

Another major study for Rio de Janeiro yields consistent findings for the most part. MotteBaumvol and Nassi (2012) report as the main factors the type of occupation and age. The level of income and residential location in low-density spaces also have significant effects but of smaller amplitude. However, educational level plays a major role in Brazil, probably because of greater inequalities in that country. Another difference relates to the role of car ownership and driving licence possession, which have no significant effect on mobility in Rio de Janeiro. 
That is again probably a difference pertaining to the specific context of Brazil where car ownership was low in 2003 (110 cars per 1000 inhabitants) (Lopes, 2005).

\section{TERRAIN}

\section{A highly segmented population on uneven relief}

The RJMA had 11.3 million inhabitants in 2003 and extended over 20 municipalities, or some $120 \mathrm{~km}$ from east to west and $50 \mathrm{~km}$ from north to south. The MRJ alone, the most extensive and most populous, concentrate $53.8 \%$ of the population. The geography of the settlement of the MRJ is marked by its position along Guanabara Bay, with its broad alluvial plain, and along the beaches facing the Atlantic Ocean. The settlement areas are dictated by the marked relief. The city is a landscape of hills and hollows. There is little or no human settlement on the steepest slopes, providing low-density zones especially within a few hundred metres of the centre (Figure 1). In the heart of the city (mainly in the Tijuca district) lies the Parque Nacional da Tijuca, a national park with one of the largest urban forests in the world.

- Figure 1: MRJ population densities, Zoning by Administrative Regions and railway infrastructures 


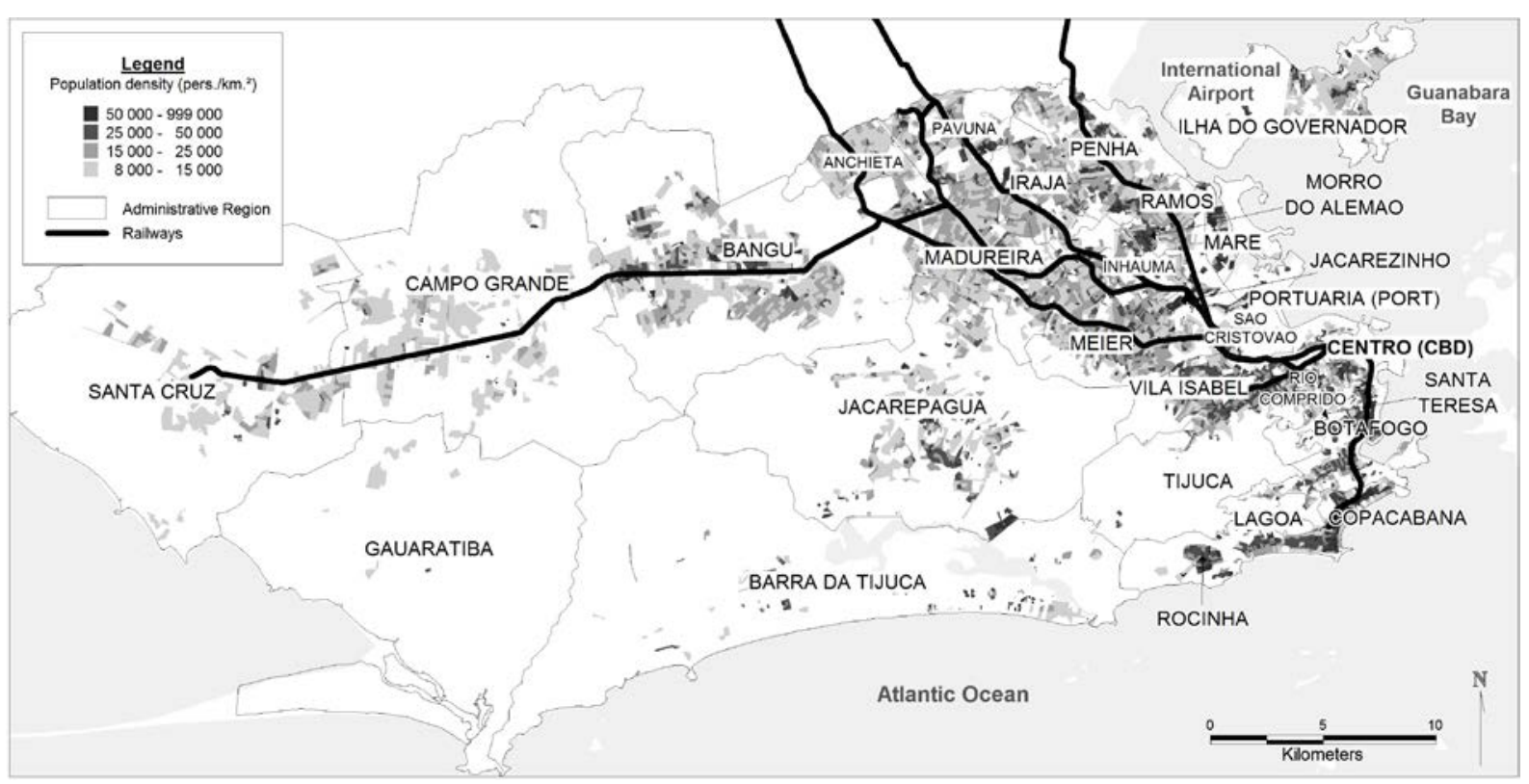

The population of Rio de Janeiro is strongly segregated between a poor or very poor northern area and a wealthy or extremely wealthy southern area. The rich live on the Atlantic coast, ever further from the centre as the city grows. The poor populations live in the many favelas on the hills overlooking the wealthy districts. But although numerous, these favelas are home to only a small proportion of the poorest population. Most of the poorest inhabitants live along Guanabara Bay and in the wide alluvial plain. The middle classes, who are poorly represented in the Brazilian population of 2003, are located rather in areas of contact between the southern and northern zones, especially in the districts of Meier and Vila Isabel (Figure 1).

\section{Strongly concentrated employment}

The Centro and the surrounding districts are the main employment centre in the MRJ with 25\% of the employment. The Centro has few inhabitants, like the CBDs of North American cities. Two other smaller employment centres, adjacent to the Centro, one to the north and the other to the south together concentrate a little over $27 \%$ of employment in the MRJ. Therefore $52 \%$ of employment is concentrated in three clustered centres in the south-east of the territory under study. Although these centres are not far from each other, the sectors of activity characterising them are different. The employment centre of the Centro is characterised by the high proportion 
of employment in services and especially public services. Employment in commerce and FIRE (Finance, Insurance, Real Estate, etc.) is well represented too. The second employment centre in the MRJ, located to the north-west of the centre around the São Cristóvão district, includes a large part of the port and is characterised by the proportion of jobs in industry and freight transport. The third employment centre is located south of the Centro of Rio de Janeiro. It is characterised by a large proportion of jobs in services, mainly specialised services and household services. The population living in the perimeter of the employment centre has a high level of income, explaining the higher proportion of housheold services and of services in general in this area. Moreover, the employment centre includes a large number of jobs in tourism as there are many hotels especially in the Copacabana district.

\section{A transport system dominated by buses}

In 2003, the population of Rio de Janeiro, as in Brazil as a whole, was characterized by its low level of car ownership with 110 cars per 1000 inhabitants versus 830 in the US (Lopes, 2005). Longer journeys are therefore made principally by public transport, with a share of $46.7 \%$ for this mode of transport of all the journeys made. But the MRJ is poorly equiped for mass transport with just three rail corridors all ending at the same dead-end railway station, Central do Brasil. There are besides just two underground lines. These public transport services are completely saturated and provide just $7.1 \%$ of journeys made by public transport. Most of the public transport is provided by a plethora of bus lines extending across the entire terrritory. Buses are plentiful and frequent. But in 2003, there were few bus lanes and these were congested. Accordingly, public transport in Rio de Janeiro is slow, irregular and uncomfortable especially during the rush hours. Moreover, the lack of season ticket, transit pass, integrated pricing or social pricing means that public transport is very expensive for much of the population (Gomide 2003). 


\section{THE MODEL AND THE METHOD}

We attempt to explain the immobility observed in the Rio HTS, which is the absence of journeys (longer than 300m) declared on the day before the respondent is surveyed, by a logistic regression model. The literature review underscores the diversity of relevant factors for explaining this immobility and so the difficulty in bringing out dominant factors. We consider here the classical socio-economic variables related to housing and lastly variables related to the residential environment.

As often in models of this kind, the variables may exhibit some degree of colinearity. Likewise, variables that are omitted because they cannot readily be observed, such as the level of amenities, including social amenities, influence a number of explanatory variables and the variable to be forecast. This is why we generally use modelling techniques that take account of spatial dependence of variables, such as geographical weighted regression (GWR). We have shown that in the case of Rio de Janeiro, there are many discontinuities because of the hilly landscape or the coastline. Accordingly we use a multi-level approach to construct our model: the respondents are characterised individually by their socio-economic characteristics and belong to spatial areas that are assumed to have homogeneous characteristics. Rather than introducing a spatial indicator into the model for each zone, which would induce correlations among individuals from the same zone, with our model we distinguish an individual effect from a zone effect. We hope in this way to highlight both individual social effects and more general spatial effects.

For this multi-level modelling, we use a generalised linear mixed-effects model (GLMM) (Agresti, 2002; Breslow and Clayton, 1993). This is an extension of the generalised linear model, which encompasses logistic regression in the case where data belong to groups and 
cases where the same individuals respond several times. In a GLMM, the group model and individual model are estimated simultaneously and it is possible to distinguish between the fixed effects of the model, that is the impact of individual variables, as in a classical regression, and the random effects of the model, that is, the differences in the population of individuals that can be explained by their membership of the various groups in question. We speak of fixed effects because it is considered that the explanatory variables in question are deterministic.

We begin by describing the fixed-effects logistic model by introducing a latent variable $Y_{i}^{*}$ :

$$
Y_{i}^{*}=X_{i} B+\varepsilon_{i}
$$

where $X_{i}$ is the vector of the individual explanatory variables and epsiloni a centred residual. We move from this latent variable to $Y_{i}$ by thresholding $Y_{i}^{*}$ :

$Y_{i}=1$ if $Y_{i}^{*}>0$, and 0 otherwise. This yields immediately:

$E\left(Y_{i} \mid X_{i}\right)=1-F\left(-X_{i} B\right)$ with $F$ the distribution function of $\varepsilon_{i}$, here the distribution function of the logistic law.

The GLMM we use assumes that the latent variable depends both on the individual $i$ and the group $j$ to which he belongs:

$$
Y_{i j}^{*}=X_{i j} B+G_{j}+\varepsilon_{i j}
$$

The term $G_{j}$ is the random term, common to all individuals in the same group, and $X_{i j}$ remains the term specific to the individual. $G_{j}$ is the variability among groups and $\varepsilon_{i j}$ the variability among individuals. $G_{j}$ can itself be decomposed as a function of the explanatory variables bearing on the groups. The $\varepsilon_{i j}$ are only conditionally independent of the random term $G_{j}$, unlike the model that would have been obtained by introducing spatial indicators for all individuals in one and the same zone. We consider the zoning by Administrative Regions which can be used 
to cluster enough individuals within each grid square for successful modelling. This is a coarser grid than the district. We test in turn a random effect by zone and a random effect by zone as a function of the category of individuals. We obtain the following results for the fixed effect of the model: Table 1.

As with all logistic regressions, these results are to be read relatively to the reference individual, who is employed, head of the household, illiterate, living in a 5-room apartment. 
- Table 1: Model results

FIXED EFFECTS

\begin{tabular}{|c|c|c|c|c|c|c|}
\hline Variable & Modality & Estimate & Std. Error & $z$ value & $\operatorname{Pr}(>/ z)$ & \\
\hline (Intercept) & & -1.022 & 0.111 & -9.232 & $<0.001$ & $* * *$ \\
\hline \multirow{3}{*}{$\begin{array}{l}\text { Employment status } \\
\text { (ref: employed) }\end{array}$} & Child & 1.324 & 0.177 & 7.748 & $<0.001$ & $* * *$ \\
\hline & Student & -0.433 & 0.096 & -4.350 & $<0.001$ & $* * *$ \\
\hline & $\begin{array}{l}\text { Inactive (unemployed, } \\
\text { housemaker, retiree, } \\
\text { pensioner) }\end{array}$ & 2.453 & 0.089 & 25.294 & $<0.001$ & $* * *$ \\
\hline \multirow{4}{*}{$\begin{array}{l}\text { Position in the } \\
\text { family (ref: } \\
\text { reference person) }\end{array}$} & Spouse & 0.454 & 0.035 & 13.982 & $<0.001$ & *** \\
\hline & Child & 0.437 & 0.035 & 12.590 & $<0.001$ & $* * *$ \\
\hline & Other relative & 0.763 & 0.047 & 16.223 & $<0.001$ & $* * *$ \\
\hline & Other & 1.457 & 0.097 & 15.020 & $<0.001$ & $* * *$ \\
\hline \multirow{6}{*}{$\begin{array}{l}\text { Education level } \\
\text { (ref: analphabet) }\end{array}$} & Pre-school & -1.648 & 0.184 & -8.928 & $<0.001$ & $* * *$ \\
\hline & Ist degree (1-4 serie) & -0.337 & 0.089 & -3.804 & $<0.001$ & $* * *$ \\
\hline & 1st degree $(5-8)$ serie & -0.460 & 0.089 & -5.188 & $<0.001$ & $* * *$ \\
\hline & $2 n d$ degree & -0.634 & 0.088 & -7.172 & $<0.001$ & $* * *$ \\
\hline & College degree & -0.915 & 0.093 & -9.875 & $<0.001$ & $* * *$ \\
\hline & Other & 1.932 & 0.204 & 9.475 & $<0.001$ & $* * *$ \\
\hline \multicolumn{2}{|c|}{ Physical disability (ref: no) } & 0,641 & 0.087 & 7.329 & $<0.001$ & $* * *$ \\
\hline \multirow{4}{*}{$\begin{array}{l}\text { Number of rooms } \\
\text { (ref: } 5 \text { and less) }\end{array}$} & 6 & 0.022 & 0.029 & 0.747 & 0.455 & \\
\hline & 7 & -0.069 & 0.042 & -1.661 & 0.097 & . \\
\hline & 8 & -0.219 & 0.050 & -4.345 & $<0.001$ & $* * *$ \\
\hline & 9 and more & -0.203 & 0.050 & -4.049 & $<0.001$ & $* * *$ \\
\hline \multirow{2}{*}{$\begin{array}{l}\text { Building type (ref: } \\
\text { apartment) }\end{array}$} & House & 0.082 & 0.028 & 2.937 & $<0.001$ & $* *$ \\
\hline & Other & 0.349 & 0.164 & 2.134 & $<0.001$ & * \\
\hline \multicolumn{7}{|l|}{ RANDOM EFFECTS } \\
\hline Groups & Name & Variance & Std.Dev. & Corr & & \\
\hline \multirow[t]{4}{*}{ Zonage HTS Rio } & $\begin{array}{l}\text { Employment status: } \\
\text { child }\end{array}$ & 0.9900 & 0.3147 & & & \\
\hline & $\begin{array}{l}\text { Employment } \\
\text { status:student }\end{array}$ & 0.2065 & 0.4544 & 0.65 & & \\
\hline & $\begin{array}{l}\text { Employment status: } \\
\text { employed }\end{array}$ & 0.2781 & 0.5274 & 0.61 & 0.90 & \\
\hline & $\begin{array}{l}\text { Employment status: } \\
\text { inactive }\end{array}$ & 0.2432 & 0.4931 & 0.55 & 0.720 .36 & \\
\hline
\end{tabular}

The fixed effects are consistent with what previous studies have taught us about the question. Immobility logically takes very different values according to the individual's type of activity. It varies from $80 \%$ for the least mobile categories, homemakers and the unemployed, to a little more than $20 \%$ for the most mobile, the employed and students. The type of activity is the main explanatory factor of immobility in the model, whereas the other variables have far lower 
explanatory power. Women and children are more likely to be immobile than the heads of households, and other relatives even more so. The less educated the individuals, the more likely they are to be immobile. Lastly, the disabled are more likely to be immobile. We also bring out effects related to housing, with lower immobility levels for people living in large houses and in apartments.

As already pointed out, some of these variables may exhibit colinearity, especially because they are related to income, which cannot be exploited in the Rio HTS because of the high nonresponse rate. Examination of the generalised variance inflation factors of the fixed-effects model shows that such colinearities are not a problem in our case and are limited. Analysis of variance of the model reveals that the individual characteristics are clearly more decisive than housing characteristics. The importance of educational level confirms the pre-eminence of employment for individuals’ immobility.

We obtain residuals for each of the 57419 individuals observed in the database. So as to highlight any spatial effects of immobility, we estimate a model including solely fixed-effects, i.e. a classical logit model, and we calculate the mean of residuals for all of the individuals in each study zone. These average residuals per zone are then mapped (Figure 2). The map reveals the expected systematic effects: immobility in the peripheral districts to the north and west of the city is underestimated (the observed probabilities of being immobile are greater than the predicted probabilities) and overestimated in the more central districts in the south-east. Our multi-level approach therefore had to be adapted to capture this effect properly. We observe that the multi-level model yields low residuals, without any spatial structure, except for the underestimation in the two northern districts. Our model probably lacks explanatory variables to take this specificity into account.

- Figure 2: Maps of averaged residuals per zone in the multi-level model 


\section{All, fixed effects}

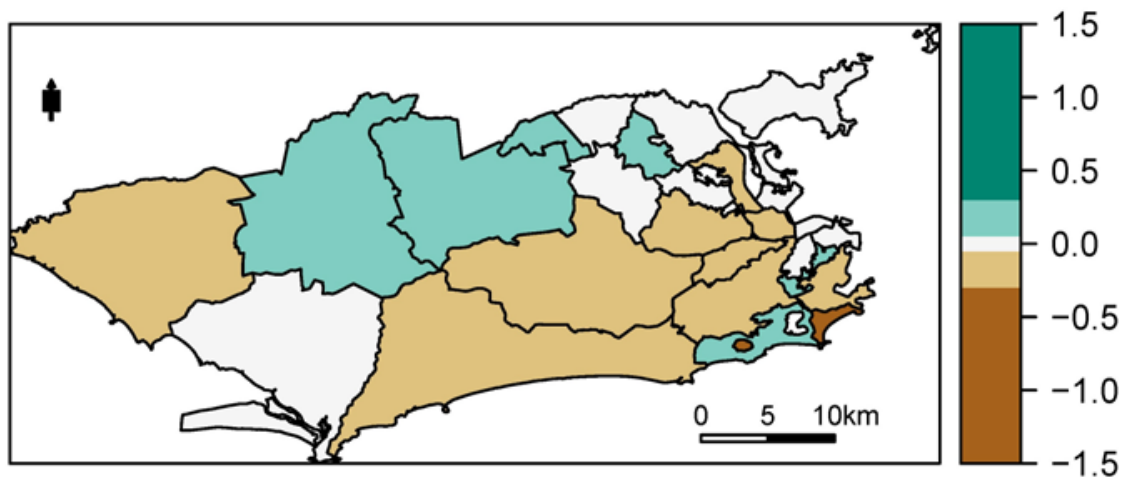

\section{Employed, random effects}

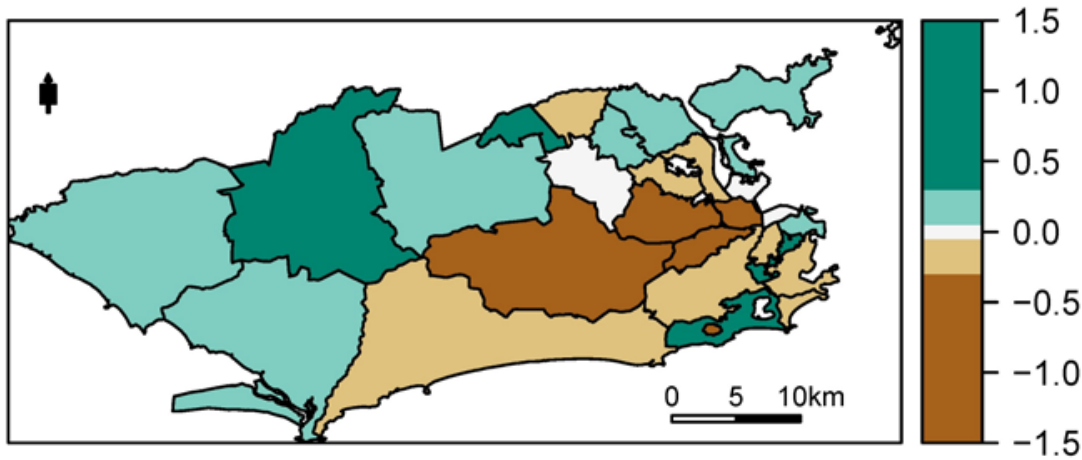

Unemployed or inactive, random effects

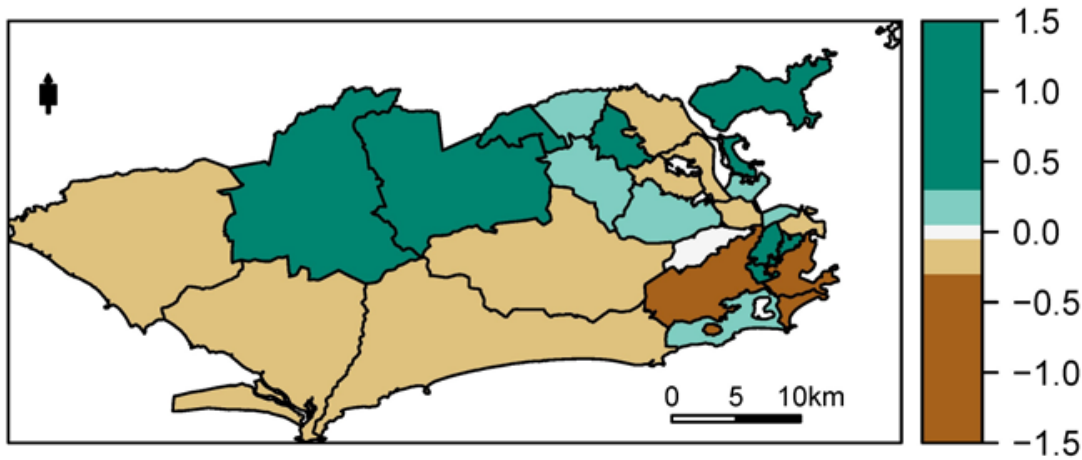

In our multi-level model, the random effects are coefficients for each of the categories of individuals and each zone. Rather than presenting the table of these coefficients, we map them so as to be able to analyse the spatial distribution of these random effects. Figure 2 shows the spatial distribution of coefficients for two categories of individuals, the employed on the one hand and the unemployed or inactive on the other. In this way, the spatial effect captured with the model is isolated. A positive zone coefficient for a category will increase the probability of being immobile for all individuals in the same zone belonging to this 
category. A negative coefficient will reduce that probability. In this way, the residual spatial effects analysed are clearly differentiated by category of individuals.

\section{RESULTS}

Beyond population structure effects, geography has a significant effect on the probability of individuals being immobile. Two types of effects have been identified in continuity with the literature analysed above. The first relates to physical barriers whether due to relief, the coastline, single-use zones or traffic barriers. Our findings show that these barriers increase the likelihood of being immobile, mainly in the poor districts of Rio de Janeiro, where walking is the most common mode of transport. The second effect relates to social fragmentation (Santos 1990), which is not a barrier for the inhabitants of very poor favelas locked within wealthy districts. On the contrary, it seems to promote their mobility because the probability of being immobile is lower in such districts. Lastly, we indicate that barriers have different effects between the employed on one side and the unemployed or inactive on the other, but also depending on individuals’ income levels.

\section{Physical barriers}

On the fixed-effects map, several zones seem to promote immobility. Among these zones, the existence of physical barriers may be highlighted for several of them and primarily for two large zones to the north-west, Campo Grande and Bangu. These peripheral zones are locked out relative to the city centre. Bangu and Campo Grande are located at the bottom of a valley the entry to which, in the east, is blocked by a large military area, with only one very wide avenue through it, the city's main traffic barrier, and a rail line into the city centre. These zones are therefore closed in on themselves and access to employment and other activities in the centre and the south of Rio de Janeiro is highly restricted. 
- Figure 3: Map of physical barriers marking the Anchieta and Iraja zone

\section{Anchieta}

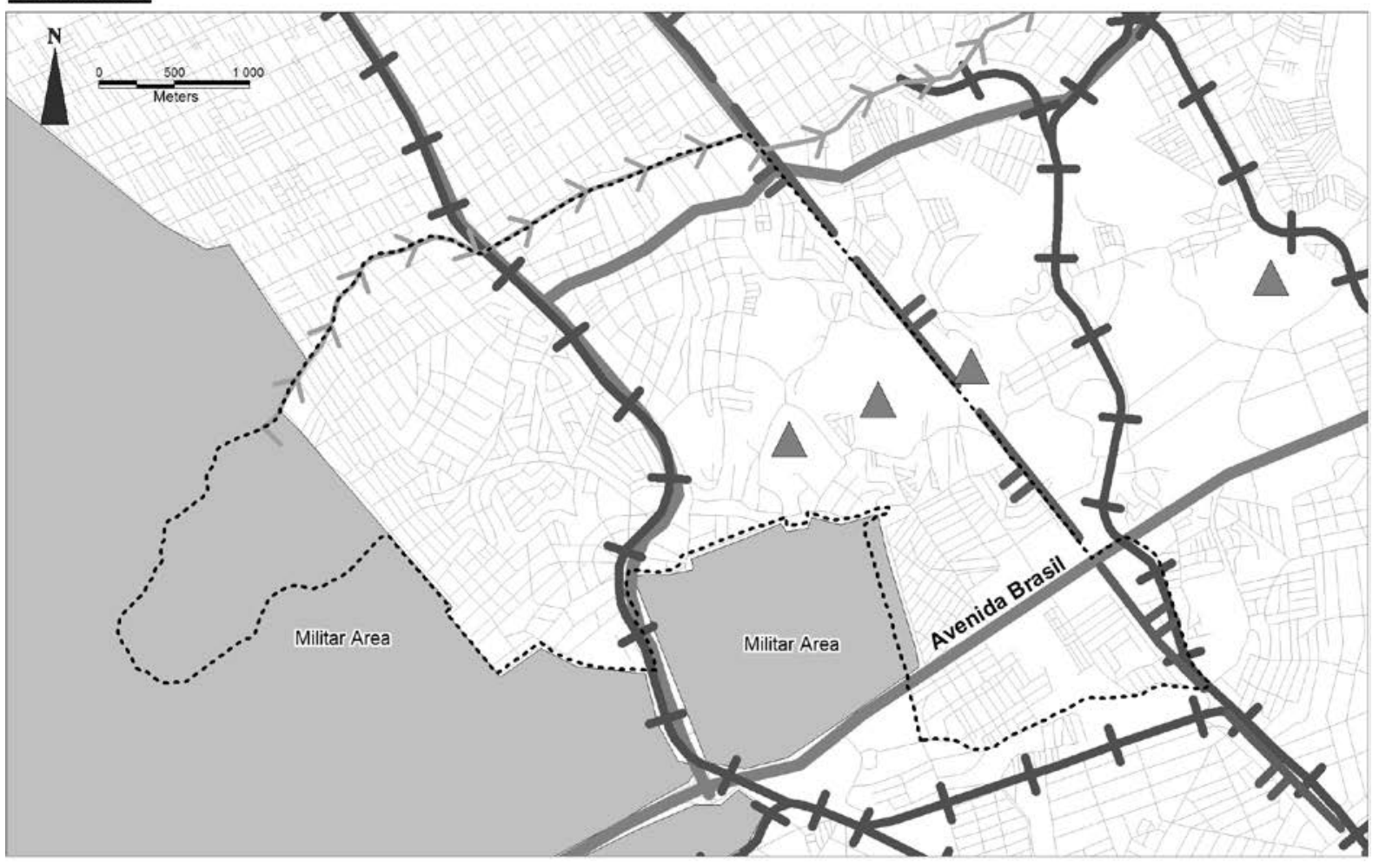

\section{Iraja}

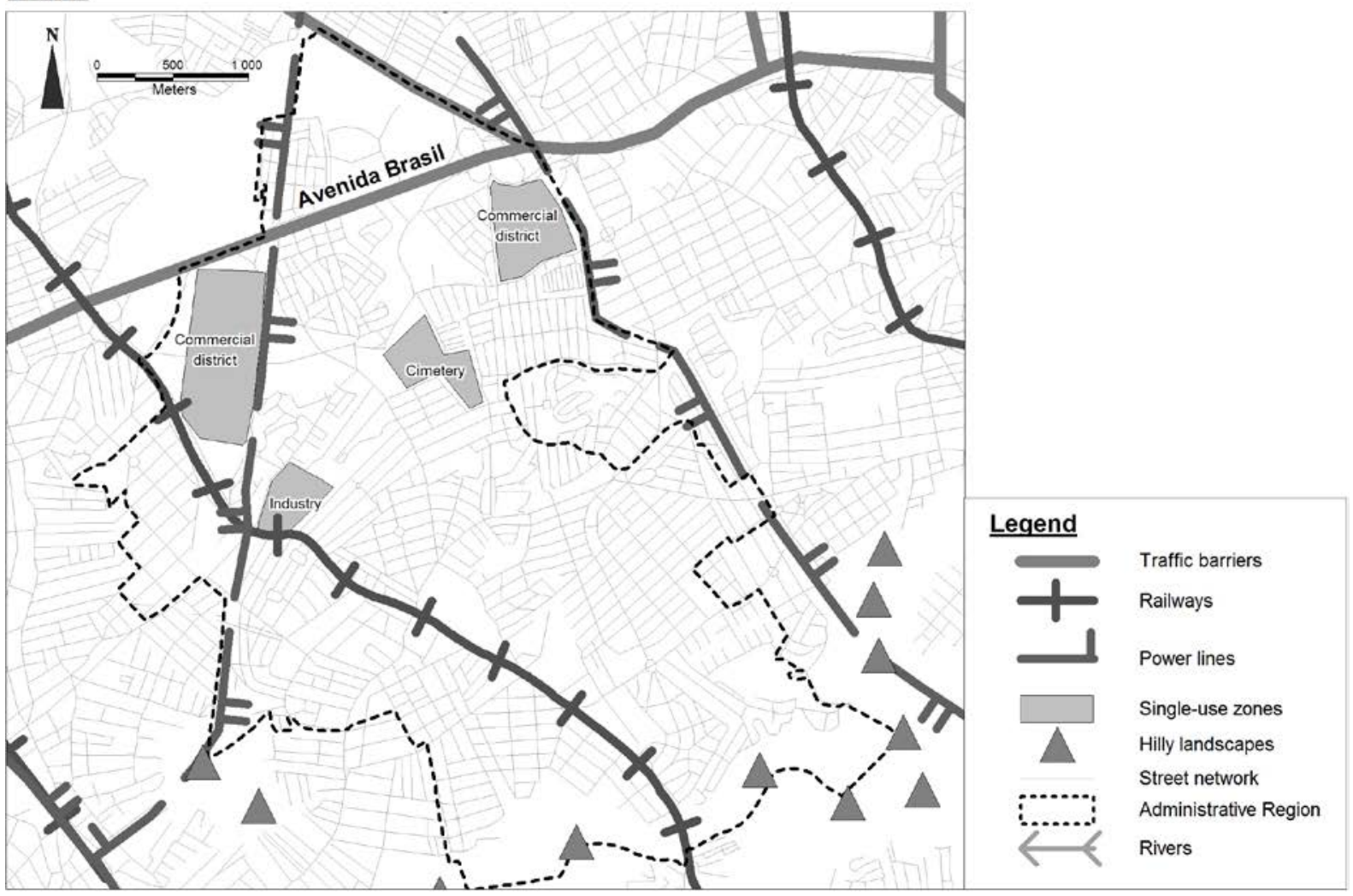


Two other zones stand out: Anchieta and Iraja. Although close to the previous two zones, their situation is different. They lie on the alluvial plain around Guanabara bay and are integrated in a huge unbroken urbanised array from the city centre of Rio Janeiro to the centres of the municipalities of Duque de Caxias and Nova Iguacu further north. Most of the RMRJ population is concentrated in this space. While urbanisation is unbroken, the two zones are relatively isolated by an impressive set of physical barriers. All the forms of barriers listed by Héran (2011) are to be found here and surround Anchieta and Iraja. In Anchieta, the Avenida Brasil flanks and cuts the southern part of the zone (Figure 3). To the north,another more modest avenue (Chrisotomo Pimentel de Oliveira) forms a traffic barrier duplicated a little further on by a river (Rio Pavuna) which is not wide but is full of waste and has few crossing points. To the west, the zone is bounded by a huge, impassable military terrain. To the east, the zone boundary is materialised by the course of three high-voltage power lines that are fenced off apart from a few crossing points (5 over a $3.5 \mathrm{~km}$ stretch). In addition to these barriers on the edges of the zone, others are to be found in the heart of Anchieta. First, the relief does not facilitate circulation between the north and south of the zone, although it is not very steep. Second, a broad avenue (Nazaré) cuts the zone from north to south. It forms a barrier that is particularly difficult to cross because the railway tracks are in the centre of the avenue and there is just one road crossing and a few pedestrian overpasses for the entire stretch (some $5 \mathrm{~km}$ ).

For Iraja, the situation is similar with different types of barriers bounding the district (Figure 3). There is the Avenida Brasil to the north, fenced off power lines to the east and west and steep relief to the south. Other barriers mark the space at the heart of this zone. Again there is a wide avenue with rail tracks (this time the metropolitan railway) along the centre and very few crossing points. The zone also includes several single-use zones (shopping centres, factories, etc.) that dissect the space a little more. 
Among the zones that have a positive effect on the probability of being immobile is Santa Teresa, which is contiguous with the city centre but is on steep relief. Whether to the north, south or east, access to other districts is by long flights of steps, a few winding streets or an cable car for tourists. The west of the zone is blocked by even steeper relief and a protected forest.

Despite many barriers, one zone has no effect on immobility and is therefore a counter-example to the previous situations, the Ilha do Governador. Yet the barriers are of two kinds. The zone is on an island, the entrance to which is blocked off by the international airport and a military base. This zone stands apart from the previous ones by the income level of the populations living there. The inhabitants of Ilha do Governador are rather well-off, which means they can travel by public transport or even by car. Besides, the international airport can supply the population of this district with many jobs and services that provide an incentive to move and leave their district.

Having analysed the situations in these various zones and compared them with the remaining zone, a few general rules can be inferred. In particular, the probability of being immobile is increased in zones with many physical barriers, where the residential function predominates and where income levels are too low to allow access to public transport and/or motor transport. Conversely, in multifunctional districts, where residential and employment functions are mixed, that are not cut-off from other districts by physical barriers that are hard to cross, and that are home to populations with moderate or high incomes, the probability of being immobile is far lower. This is the case of Copacabana, Botafogo, Tijuca, Jacarepagua and Vila Isabel.

\section{Social fragmentation: symbolic and perceptive barriers}

Spatial fragmentation produces effects on immobility, but those effects do not operate in the sense expected, in particular by Santos (2009). The probability of being immobile is lower in 
favelas such as Rocinha that is adjacent to the wealthiest areas of Rio de Janeiro located in the Lagoa zone. Conversely, the inhabitants of the rich Lagoa zone are far more likely to be immobile. Thus social fragmentation and symbolic and perceptive barriers affect rather the wealthiest populations surrounded by less well-to-do zones, who prefer to remain in their district and move only in the immediate vicinity of their homes if at all.

\section{The geography of immobility tested by type of activity}

The geography of immobility varies by the category of individuals and especially depending on their type of activity (Figure 2). Compared with the effects studied previously, the physical barriers affect the unemployed or inactive a little more. For this category of individuals, whether poor or rich, the probability of being immobile is high in the zones with physical barriers studied above such as Campo Grande, Iraja, Anchieta and Santa Teresa. But in addition, these categories are more likely to be immobile than in Ilha do Governador, unlike the employed. Indeed, while the employed go to work outside the zone with few jobs to offer, the unemployed or inactive find most of their necessary resources locally. This category is therefore more immobile or makes short journeys on foot that are not counted in the HTS.

As for social fragmentation, its effect on immobility is more pronounced for the employed than the unemployed or inactive. But no reverse effect is found between categories of individuals as is the case for physical barriers.

\section{DISCUSSION - CONCLUSION}

While the characteristics of individuals and in particular the type of activity are the main explanatory factors for immobility, our findings from a GLMM show a geographical dimension to immobility and to local dependence that goes beyond the population structure effect. This 
dimension is related first to physical barriers: traffic barriers, single-purpose zones, walls, steep relief which are plentiful and profoundly mark the territory of Rio de Janeiro. In several zones of the city, the greater likelihood of being immobile corresponds to the presence of many physical barriers that can only be crossed with some degree of difficulty. And yet, the barrier effects do not affect all populations in the same way. First, the poor and inactive are the most concerned, especially because they generally travel on foot. Barriers require them to make detours and extra effort that limits their journeys especially when public transport is too costly (Gomide 2003). For the more well-to-do working population who travel by public transport or by car, the physical barrier effects are much more limited, or even non-existent, such as for the working population living in Ilha do Governador.

Social fragmentation (Santos 2009) that strongly marks the territory of Rio de Janeiro also has an effect on immobility, measured by the HTS. But in the case of favelas caught up among wealthy districts, fragmentation leads to increased mobility. In particular for the employed population, these districts are those where the probability of being immobile is lowest. The nearby wealthy districts provide many opportunities for jobs for poorly qualified and poor workers, especially in shops or domestic services. By contrast, the inhabitants of the wealthy districts of the Lagoa zone, who are among the richest in the city, are more likely to be immobile. We hypothesise that these individuals surrounded by poorer than them remain within their districts, where shops, services and even jobs for them are to be found.

In terms of public policies, our findings highlight several way to reduce the number of immobile individuals. First, providing crossing points and developing the approaches to physical barriers formed by certain infrastructures, single-use zones, relief or insular situation are actions that can modulate the levels of immobility. In the case of Rio de Janeiro such barriers are very plentiful and the proposed crossing points are often few and not suitable for everyone. 
Secondly, improved access to public transport in terms of charges and fare integration might have a substantial effect on the level of immobility of the working population. Since 2003, fare integration has been gradually introduced but there are still no subscription arrangements for most people to use public transport regularly. Thirdly, excessively prominent zoning and high concentration of shops and activities leads to increased immobility in peripheral residential districts. Recommending planning with a greater mix of functions would also make it possible to modulate levels of immobility.

\section{References}

Adey P (2006). If mobility is everything then it is nothing: towards a relational politics of (im)mobilities. Mobilities, 1(1), 75-94.

Agresti A (2002). Categorical data analysis. Hoboken, NJ: John Wiley and Sons.

Appleyard D, Gerson M.S, and Lintell M (1981). Livable streets, protected neighborhoods. University of California Press.

Appleyard D, and Lintell M (1972). The environmental quality of city streets: the residents' viewpoint. Journal of the American Institute of Planners, 38 (2), 84-101.

Armoogum J, Castaigne M, Hubert J-P, and Madre J-L (2005). Immobilité et mobilité observées à travers les enquêtes ménages de transport ou d'emploi du temps. In Xèmes journées de méthodologie statistique. Paris, France: INSEE.

Axhausen K W, Löchl M, Schlich R, Buhl T, and Widmer P (2007). Fatigue in long-duration travel diaries. Transportation, 34(2), 143-160. 
Axhausen K W, Zimmermann A, Schönfelder S, Rindsfüser G, and Haupt T (2002). Observing the rhythms of daily life: A six-week travel diary. Transportation, 29(2), 95-124.

Bacqué M, and Fol S (2007). Inequality regarding mobility: observations and policies. Swiss Journal of Sociology, 33(1), 89-104.

Barrère A, and Martuccelli D (2005). La modernité et l'imaginaire de la mobilité : l'inflexion contemporaine. Cahiers internationaux de sociologie, $\mathrm{n}^{\circ} 118$ (1), 55-79.

Boltanski L, and Chiapello È (1999). Le nouvel esprit du capitalisme. Gallimard.

Breslow N E, and Clayton D G (1993). Approximate inference in generalized linear mixed models. Journal of the American Statistical Association, 88(421), 9-25.

Capron G (2002). Accessibility to Modern public spaces’ in Latin-American cities: a multidimensional idea. GeoJournal, 58 (2-3), 217-223.

CENTRAL (2005). Plano Diretor de Transporte Urbano da Região Metropolitana do Rio de Janeiro: Resultatos da Pesquisa Origem e Destino. Rio de Janeiro: Governo do Estado do Rio de Janeiro.

Chétry, M. (2013). La fragmentation: un nouveau regard sur la ville brésilienne?, In Carrel M, Cary P, and Wachsberger JM (Eds.), Ségrégation et fragmentation dans les métropoles: Perspectives internationales, 121-136. Villeneuve d’Ascq (France): Presses Universitaires du Septentrion.

Chlond B, Lipps O, Manz W, and Zumkeller D (1999). Auswertung zum Deutschen Mobilitäts-Panel 1998/1999: Haushaltsbefragung zur Alltagsmobilität in verschiedenen Raumtypen. Final report FE-Projekt, 70569, 98. 
Coutard O, Dupuy G, and Fol S (2004). Mobility of the poor in two european metropolises: car dependence versus locality dependence. Built environment, 30(2), 138-145. Retrieved April 1, 2015,

Cresswell T (2010). Towards a politics of mobility. Environment and planning. D, Society and space, 28(1), 17.

Vasconcellos E A (2005). Transport metabolism, social diversity and equity: The case of São Paulo, Brazil. Journal of Transport Geography, 13(4), 329-339.

Fol S (2009). La mobilité des pauvres. Paris: Belin.

Gomide A (2003). Transporte urbano e inclusão social: elementos para políticas públicas. Brasilia: IPEA.

Guerrien M (2004). Transformation et fragmentation des espaces urbains. Le cas de la zone métropolitaine du bassin de Mexico. L’Espace géographique, (4), 336-352.

Hannam K, Sheller M, and Urry J (2006). Editorial: Mobilities, Immobilities and Moorings. Mobilities, 1 (1), 1-22.

Héran F (2009. Des distances à vol d'oiseau aux distances réelles ou de l'origine des détours. Flux, 76-77 (2), 110-121.

Héran F (2011). La ville morcelée. Paris: Économica.

Hine J, and Russell J (1993). Traffic barriers and pedestrian crossing behaviour. Journal of Transport Geography, 1 (4), 230-239. 
Hubert J-P, Armoogum J, Axhausen K W, and Madre J-L (2008). Immobility and Mobility Seen Through Trip-Based Versus Time-Use Surveys. Transport Reviews, 28(5), 641658.

Jacobs J (1961). The death and life of American cities.

James E, Millington A, and Tomlinson P (2005). Understanding community severance I: views of practitioners and communities. London: Department for Transport.

Jouffe Y, and Lazo Corvalán A (2010). Las prácticas cotidianas frente a los dispositivos de la movilidad: Aproximación política a la movilidad cotidiana de las poblaciones pobres periurbanas de Santiago de Chile. EURE (Santiago), 36 (108), 29-47.

Kaufmann V, Bergman M M, and Joye D (2004). Motility: mobility as capital. International journal of urban and regional research, 28(4), 745-756.

Lévy J (2000). Les nouveaux espaces de la mobilité. In: M. Bonnet and D. Desjeux, eds. Les territoires de la mobilité. Paris: Presses universitaires de France, 155-170.

Lopes S P (2005). Development of Mathematics Models for Analysis, Evaluation and Forecast of the Motorisation Behavior in Brazil (PhD Thesis). Federal University of Rio de Janeiro, Rio de Janeiro.

Madre J-L, Axhausen KW, and Brög W (2007). Immobility in travel diary surveys. Transportation, 34 (1), 107-128.

Montulet B (2005). Au-delà de la mobilité : des formes de mobilités. Cahiers internationaux de sociologie, 118 (1), 137-159. 
Motte-Baumvol B, and Nassi C.D (2012). Immobility in Rio de Janeiro, beyond poverty. Journal of Transport Geography, 24, 67-76.

Noonan D S (2005). Neighbours, barriers and urban environments: are things' different on the other side of the tracks’? Urban Studies, 42(10), 1817-1835.

Orfeuil J-P (2004). Accessibilité, mobilité, inégalités: regards sur la question en France aujourd’hui. Transports, pauvretés, exclusions, Paris, Éditions l’Aube, 27-47.

Park R.E (1926). The urban community as a spatial pattern and a moral order. The urban community, 3-18.

Pellegrino G (2011). Studying (Im) mobility through a Politics of Proximity. In G Pellegrino (Ed.), The Politics of Proximity: Mobility and Immobility in Practice (1-14). Farnham UK: Ashgate.

Pochet P (2003). Mobilité et accès à la voiture chez les personnes âgées: évolutions actuelles et enjeux. Recherche-Transports-Sécurité, 79, 93-106.

Rémy J (1996). Mobilités et ancrages: vers une autre définition de la ville. In M Hirschorn, and J M Berthelot (Eds.), Mobilités et ancrages. Vers un nouveau mode de spatialisation? (135-153). Paris: L’Harmattan.

Rodríguez J, and Arriagada C (2004). Segregación residencial en la ciudad latinoamericana. Eure (Santiago), 30 (89), 05-24.

Sabatini F (2006). The social spatial segregation in the cities of Latin America. InterAmerican Development Bank. 
Santos M (2009). Metropole corporativa fragmentada: o caso de São Paulo. São Paulo:

Editora Edusp.

Urry J (2007). Social inequalities in network capital. Swiss Journal of Sociology, 33(1), 9-26.

Uteng T P, and Cresswell T (2008). Gendered Mobilities. Farnham UK: Ashgate. 